\title{
Effects of Fe-6.5wt.\%Si alloys prepared by different cooling methods on ordered structure and mechanical properties
}

Dongpo Xuan

Cheng Zhou ( $\nabla$ zhouc_107@126.com )

University of Science and Technology Beijing

You Zhou

Tianliang Jiang

Biji Zhu

Wenhao Fan

\section{Research Article}

Keywords: Fe-6.5wt.\%Si alloy, strip casting, room temperature plasticity, ordered phase, reverse domain boundary

Posted Date: February 15th, 2022

DOI: https://doi.org/10.21203/rs.3.rs-1343364/v1

License: (1) This work is licensed under a Creative Commons Attribution 4.0 International License. Read Full License 


\section{Abstract}

The non-oriented Fe-6.5wt.\%Si alloy cast strip with a width of $100 \mathrm{~mm}$ and a thickness of $1.7 \mathrm{~mm}$ was prepared by the top side-pouring twin-roll casting (TSTRC) process. The surface quality of the air-cooled and water-cooled cast strip was good. Compared with the Fe-6.5wt.\%Si alloy ingot, the Fe-6.5wt.\%Si alloy cast strip has a relatively fine solidification structure and exhibits certain plasticity at room temperature. Microhardness, XRD, and TEM investigated the ordered structure and degree of Fe-6.5wt.\%Si alloys prepared by three different cooling methods. The results show that the Fe-6.5wt.\%Si alloy ingot prepared by the standard method has many $\mathrm{B}_{2}$ ordered phases and $\mathrm{DO}_{3}$ ordered phases, and the order degree is high. The Fe-6.5wt.\%Si alloy cast strip prepared by the TSTRC process has a low degree of order and only contains a small $\mathrm{B}_{2}$ ordered phase. The faster cooling rate effectively inhibits the formation of the $\mathrm{DO}_{3}$ ordered phase and $\mathrm{B}_{2}$ ordered phase. The growth of the ordered phase also reduces the reverse domain boundary energy, reduces the motion resistance of superdislocations, and increases its mobility, thereby improving the room temperature plasticity of Fe-6.5wt.\%Si alloy cast strips.

\section{Introduction}

Fe-6.5wt.\%Si alloy is an excellent soft magnetic material with high permeability, low coercivity, and nearzero magnetostrictive properties [1-3]. It is an essential magnetic material in the power and telecommunication industries. However, when the mass fraction of Si reaches $6.5 \%$, ordered phases of B2 (FeSi) and D03 (Fe3Si) appear in the Fe-6.5 wt.\% Si alloy, leading to a dramatic increase in material brittleness and hardness. Due to the limited formability and ductility of the material, it is difficult to roll it into thin sheets using conventional rolling methods. The low-cost batch preparation of Fe-6.5wt.\%Si alloy sheet cannot be realized under the existing production conditions of the steel mill, which seriously limits its large-scale application and thus affects its wide application [4-6].

In order to avoid the brittle processing range of Fe-6.5wt.\%Si alloy to prepare alloy sheet, new preparation techniques have been attempted to prepare Fe-6.5wt.\%Si alloy sheets, such as powder rolling process [7, 8], chemical vapor deposition (CVD) [9-11], rapid solidification [12,13], directional solidification [14-16], and twin-roll strip casting [17]. Yuan et al. [8] used atomized Fe powder and Si powder as raw materials and used powder rolling technology to obtain a powder strip with a width of $65 \mathrm{~mm}$ and a thickness of $0.39 \mathrm{~mm}$ to $0.44 \mathrm{~mm}$, and then through sintering and rolling obtained $0.3 \mathrm{~mm}$ thick sheet. However, the direct powder rolling method has disadvantages such as easy oxidation of raw material particles, difficulty in mixing the particles uniformly, poor density after sintering, and difficulty in controlling the shape of the plate. At present, the CVD method developed by Japan's NKK Company (now JFE Company) can produce Fe-6.5wt.\%Si alloy sheets of $0.1 \sim 0.5 \mathrm{~mm} \times 400 \mathrm{~mm}$, but there are still long process time, large environmental burden, low productivity and high cost. The problem is that this method has not been generally accepted by the steel industry. Raviprasad [18] found that rapid solidification completely inhibited the formation of $\mathrm{DO}_{3}$ ordered phase in Fe-6.5wt.\%Si alloys. Although it did not completely inhibit the formation of $B_{2}$ ordered phase, the ordered domains of $B_{2}$ ordered phase were small. Arail et al. [12, 
13] successfully prepared amorphous ribbons with various thickness and width specifications, smooth surface, and flat plate shape by rapid solidification process, and successfully prepared 20-150 $\mu \mathrm{m}$ thick, various specifications of $\mathrm{Fe}-6.5 \mathrm{wt}$.\%Si alloy thin strips ranging from 2-25 $\mathrm{mm}$ in width and $5 \sim 10 \mathrm{~m}$ in length. However, the amorphous ribbon prepared by this process is severely limited in product size and specification. It cannot be used to make iron cores for large electrical equipment, so this technology's development potential and product application prospects are limited. Xie et al. [14-16] prepared highsilicon steel ingots with columnar crystals by directional solidification technology. They integrated various methods such as composition optimization control, grain boundary morphology control, organization orientation control, deformation softening, and heat treatment plasticization. By adjusting and controlling, a new process of warm-cold rolling and high-efficiency forming of high-silicon electrical steel strips is realized, and Fe-6.5wt.\%Si alloy strips with a thickness of $0.2 \mathrm{~mm}$ are prepared. However, this method has not been realized in industrialized production. The Wang Guodong team used the twinroll cast strip continuous casting technology to obtain $2.5 \mathrm{~mm}$ cast strips directly from liquid high silicon steel. After hot rolling, warm rolling, and cold rolling, the Fe-6.5wt.\%Si alloy cast strip was successfully prepared with different thicknesses. Among these new methods, the twin-roll strip casting process is a simple and effective method for producing Fe-6.5wt.\%Si alloys, which directly prepares the molten melt into cast strips with a thickness close to that of traditional hot-rolled sheets. The process has the benefit of extremely rapid cooling, reduced component segregation, and grain refinement, which not only reduces energy consumption, improves process efficiency, and saves costs, but also achieves good mechanical properties [19] and ideal $<001>/ / \mathrm{ND}$ ( $\lambda$-fiber) texture [20]. Due to various advantages of this process, it is a very feasible method to prepare Fe-6.5wt.\%Si alloy sheets.

Our laboratory adopts the (TSTRC) process to directly pass the molten melt through a rotating crystallization roller to prepare a non-oriented Fe-6.5wt.\%Si alloy cast strip with a thickness of $1.7 \mathrm{~mm}$ and a width of $100 \mathrm{~mm}$, and the surface quality of the cast strip is good [21]. In this paper, the mechanical properties of the Fe-6.5wt.\%Si alloy in the cast Fe-6.5wt.\%Si alloy and the Fe-6.5wt.\%Si alloy cast strip prepared by TSTRC were compared under the conditions of air-cooled and water-cooled. The effect of order relative material mechanical properties in Fe-6.5wt.\%Si alloys under different cooling conditions was investigated, revealing the room temperature brittleness nature of Fe-6.5wt.\%Si alloys.

\section{Experimental Procedure}

Table 1

Chemical composition of the Fe-6.5wt\%Si alloy (wt.\%)

\begin{tabular}{|lllllll|}
\hline Element & $\mathbf{S i}$ & $\mathbf{C}$ & $\mathbf{S}$ & $\mathbf{P}$ & $\mathbf{N}$ & $\mathbf{F e}$ \\
\hline Content & 6.45 & 0.006 & 0.005 & 0.006 & 0.003 & Bal. \\
\hline
\end{tabular}

The initial raw materials are $99.99 \%$ industrial pure iron and $99.99 \%$ industrial pure silicon as raw materials and are smelted in a vacuum induction furnace to prepare Fe-6.5wt.\%Si alloy ingots. Then use TSTRC to do experiments, and use TSTRC to prepare $100 \times 1.7 \mathrm{~mm}$ non-oriented Fe-6.5wt.\%Si alloy cast strips. The cast strips were cooled in air and sprayed with water, respectively. The chemical composition 
of Fe-6.5wt.\%Si alloy is shown in Table 1. The preparation process of the three Fe-6.5wt.\%Si alloys and the Fe-6.5wt.\%Si alloy ingots, air-cooled cast strip, and water-cooled cast strip is shown in Fig. 1.

The microstructure and mechanical properties of ordinary as-cast ingots, air-cooled, and water-cooled strips were analyzed. Various samples were cut from Fe-6.5wt.\%Si alloys prepared by three different processes for subsequent characterization tests. The $10 \times 10 \mathrm{~mm}$ samples were mechanically ground with 240\#, 400\#, 1000\#, 2000\#, and 3000\# sandpapers in turn and then polished. After corrosion in a mixture of $8 \% \mathrm{HNO}_{3}$ and $92 \% \mathrm{C}_{2} \mathrm{H}_{5} \mathrm{OH}$ for $48 \mathrm{~s}$, the microstructure was observed on an optical microscope (OM). The microhardness test was carried out on the FM-700 microhardness tester. The sample preparation process was the same as the metallographic sample preparation method. The load was $500 \mathrm{gf}$, the recording time was $5 \mathrm{~s}$, and the loading speed was $50 \mu \mathrm{m} / \mathrm{s}$. Find ten different locations for hardness testing, then remove the highest and lowest values, and take the average to get the hardness value. An electronic universal testing machine tested the material's room temperature tensile mechanical properties, and the tensile speed was $0.5 \mathrm{~mm} / \mathrm{min}$. Use an ultrasonic cleaner to clean the tensile fracture, and then observe the morphology of the fracture under a scanning electron microscope (SEM). The $22 \times 20 \mathrm{~mm}$ sample was mechanically sanded with $240 \#, 400 \#, 1000 \#$, and $2000 \#$ sandpaper in turn, and soaked in $5 \% \mathrm{HCL}$ deionized water solution for about $30 \mathrm{~s}$, and then phase detection was carried out on an X-ray diffractometer with a scanning speed of $1^{\circ} / \mathrm{min}$ and a scanning range of $20-90^{\circ}$. The $10 \times 10 \mathrm{~mm}$ sample was mechanically ground to $50 \mu \mathrm{m}$, and a $\varphi 3 \mathrm{~mm}$ disc was punched out from the sheet with a unique tool. Then, a TenePol-5 electrolytic double jet was used to make a $\varphi 3 \mathrm{~mm}$ disc into a standard transmission sample with a specific thin area. The electrolytic double jet was a mixed solution of $5 \%$ $\mathrm{HCLO}_{4}$ and $95 \% \mathrm{C}_{2} \mathrm{H}_{5} \mathrm{OH}$, the double jet voltage was $30 \mathrm{~V}$, and the temperature was $-20^{\circ} \mathrm{C}$. The ordered phase morphology, size, and distribution of Fe-6.5wt.\%Si alloys prepared by three processes were observed by transmission electron microscopy (TEM) under the dark field.

\section{Results}

\subsection{Solidification structure}

Figure 2a, b, c shows the microstructures of Fe-6.5wt.\%Si alloy ingot, air-cooled strip, and water-cooled strip, respectively. The structure of the typical ingot obtained by the vacuum induction furnace is very coarse, and the size can reach $1 \mathrm{~mm}$. However, the structures of the cast strips prepared by TSTRC are relatively fine. The average grain size of the microstructure of the air-cooled cast strip is $242 \mu \mathrm{m}$, and the average grain size of the water-cooled cast strip is $143 \mu \mathrm{m}$. In terms of grain refinement, the TSTRC method has obvious advantages. Under the condition of slow cooling of the ingot, the heat transfer rate of the material decreases, resulting in a decrease in the temperature gradient of the liquid-solid interface during the solidification process, which inhibits the growth of columnar crystals. At the same time, the reduction of the temperature gradient promotes the supercooling of components at the front of the solidliquid interface and the nucleation of equiaxed crystals. During the TSTRC process, a strongly stirring vortex is formed as the melt flows into the micro melt-pool. Under momentum stirring, it is beneficial to 
strengthen the heat exchange between the molten metal and the cooling roll, reduce the temperature of the melt-pool, improve the degree of subcooling and the nucleation rate, and thus refine the grains. At the same time, it is also beneficial to promote the uniform temperature of each part of the melt-pool and reduce the temperature gradient. The momentum stirring of the eddy current can produce shearing action to break the dendrite arms, and the broken dendrite arms are brought to the center of the melt-pool as new nucleation cores through the reflux of the melt in the melt-pool. Thus, the formation and growth of equiaxed crystals are promoted.

\subsection{Microhardness}

The Fe-6.5wt.\%Si alloy is highly hard and brittle due to the presence of $\mathrm{B}_{2}$ and $\mathrm{DO}_{3}$ ordered phases, so the variation of ordered phases in the Fe-6.5wt.\%Si alloy can be reflected from the side by measuring the hardness of the Fe-6.5wt.\%Si alloy samples. Alcala et al. [22] found a functional relationship between the contact surface deformation of the Vickers microhardness indenter and the work hardening index.

Furthermore, through the finite element method simulation calculation concluded that the material with different work-hardening index in the microhardness test, the material surface in contact with the indenter, has two primary deformation modes, such as Fig. 3a sink-in and Fig. 3b pile-up. When the sink-in deformation occurs on the material's surface, the material is considered to have a relatively high work hardening index. The work hardening index of the material is considered low when a pile-up deformation pattern occurs on the surface of the material. Therefore, the change in the chemical hardening index of the material can be analyzed by observing and judging the microhardness test and the surface deformation of the microhardness contact surface. In turn, it reflects the content of ordered phases in Fe6.5wt.\%Si alloys under different cooling methods.

The hardness of Fe-6.5wt.\%Si alloy under different cooling methods was tested, and the topography of the contact surface of the indenter was collected. As shown in Fig. 7, the hardness values of the three materials are $396.5 \mathrm{HV}, 371.2 \mathrm{HV}$, and $362.7 \mathrm{HV}$, respectively. Figure 5 shows the microhardness indentation surface morphology of Fe-6.5wt.\%Si alloy. It can be seen from Fig. 4a that the deformation of the Fe-6.5wt.\%Si alloy ingot sample in contact with the indenter is Sink-in, indicating that the ingot is processed under the condition of slow cooling, the hardening index is high, and the order within the material is high. In Fig. 4b and Fig. 4c, the deformation modes of the Fe-6.5wt.\%Si alloy cast strip samples in contact with the indenter are all pile-up. However, the accumulation degree of Fig. $4 \mathrm{c}$ is higher, indicating that the work hardening index of the air-cooled strip and the water-cooled strip of Fe- $6.5 \mathrm{wt} . \% \mathrm{Si}$ alloy is the work hardening index of the water-cooled strip is relatively low. The water-cooled strip of Fe$6.5 \mathrm{wt} . \% \mathrm{Si}$ alloy has the lowest order degree, the air-cooled strip and the ingot have the highest order degree.

\subsection{Effect of cooling rate on the ordered structure}

Figure 5 shows the XRD patterns of three Fe-6.5wt.\%Si alloy ingots, air-cooled strips, and water-cooled strips. It can be seen from the figure that Fe-6.5wt.\%Si alloy ingots have strong XRD patterns. The Fe- 
6.5wt.\%Si alloy ingot has a strong super-diffraction peak in the $\mathrm{B}_{2}$ ordered phase, and a super-diffraction peak in the $\mathrm{DO}_{3}$ ordered phase can be observed. In both the air-cooled and water-cooled cast strips of Fe6.5wt.\%Si alloy, no super-diffraction peaks of the $\mathrm{DO}_{3}$ ordered phase are found, and the super-diffraction peaks of the B2 ordered phase are weaker in both the water-cooled strips than in the air-cooled cast strips. This is due to the higher cooling rate of the air-cooled and water-cooled zones, where the $\mathrm{DO}_{3}$ ordered phase is suppressed, and the $\mathrm{B}_{2}$ ordered phase is less abundant, which is also consistent with the results of the microhardness analysis above.

In order to further analyze the morphology and order degree of the ordered phases of the three samples, the ordered structures of the three samples were observed by TEM. The figure's selected area electron diffraction pattern of the [110] crystal belt axis can simultaneously reflect the diffraction spots of the $A_{2}$, $\mathrm{B}_{2}$, and $\mathrm{DO}_{3}$ phases. The ordered domain structures of the $\mathrm{B}_{2}$ and $\mathrm{DO}_{3}$ phases can be observed through the dark-field images of these diffraction spots. Figure 6a shows the SAED and dark field images of Fe6.5wt.\%Si alloy ingots under the [110] crystal band axis. It can be seen from the diffraction pattern that the diffraction spots of the $B_{2}$ ordered phase and the $1 / 2\{111\}$ and $1 / 3\{111\}$ diffraction spots of the $\mathrm{DO}_{3}$ ordered phase are bright, indicating that Fe-6.5wt.\%Si alloy under the condition of slow cooling rate, the content of $\mathrm{B}_{2}$ ordered phase and $\mathrm{DO}_{3}$ ordered phase is very high. From the dark field image in Fig. 6a, we can see the clear reverse domain boundary of the $B_{2}$ ordered phase. As the $B_{2}$ ordered phase is equiaxed and exhibits no crystallographic directionality, the observed boundary of the reverse domain of the $B_{2}$ ordered phase has a smooth curved shape and no regular shape. It can also be seen from the figure that the size of the $\mathrm{B}_{2}$ ordered phase is relatively large, about $2 \mu \mathrm{m}$. The $\mathrm{DO}_{3}$ ordered phase is granular and dispersed, and the size is small, about $14.3 \mathrm{~nm}$. Figure $6 \mathrm{~b}$ shows the SAED and dark field images of the Fe-6.5wt.\%Si alloy air-cooled cast strip under the [110] crystal ribbon axis. It can be seen from the diffraction pattern that the brightness of the diffraction spots of the $B_{2}$ ordered phase is weakened, and the $1 / 2\{111\}$ and $1 / 3\{111\}$ diffraction spots of the $D_{3}$ ordered phase have not been observed. This indicates that Fe-6.5wt.\%Si alloy has a lower content of $\mathrm{B}_{2}$ ordered phase under the condition of a faster cooling rate. The content of the $\mathrm{DO}_{3}$ ordered phase is so weak that $1 / 2\{111\}$ and $1 / 3\{111\}$ diffraction spots are not found in the diffraction spot pattern. It can be seen from the dark field image in Fig. $6 \mathrm{~b}$ that most of the reverse domain boundaries of the $B_{2}$ ordered phase are still in a smooth and curved shape, without regular shapes, and some reverse domain boundaries are distributed in a round block shape. The size of the $B_{2}$ ordered domains is relatively small, about $49.8 \mathrm{~nm}$. Figure $6 c$ shows the SAED and dark field images of the Fe-6.5wt.\%Si alloy water-cooled cast strip under the [110] crystal ribbon axis. It can be seen from the diffraction pattern that the brightness of the $\{111\}$ diffraction spots of the $B_{2}$ ordered phase is weak, and the $1 / 2\{111\}$ and $1 / 3\{111\}$ diffraction spots of the $\mathrm{DO}_{3}$ ordered phase cannot be observed. This shows that the Fe-6.5wt.\%Si alloy has a shallow content of $\mathrm{B}_{2}$ ordered phase under the condition of fast cooling rate, and $\mathrm{DO}_{3}$ ordered phase is wholly suppressed. It can be seen from the dark field image in Fig. $6 \mathrm{c}$ that the reverse domain boundaries of the $\mathrm{B}_{2}$ ordered phase are distributed in clusters. The size of 
$\mathrm{B}_{2}$ ordered domains is relatively small, about $17.6 \mathrm{~nm}$. To sum up, the ordering degree of the three samples is from large to small: as-cast ingot, air-cooled cast strip, and water-cooled cast strip.

\subsection{Effect of cooling rate on mechanical properties}

Figure 7 shows the room temperature tensile curves of Fe- $6.5 \mathrm{wt}$.\%Si alloys prepared by different cooling methods. The figure shows that the fracture planes of the three samples are all perpendicular to the tensile axis. The Fe-6.5wt.\%Si alloy ingot sample breaks during the elastic deformation stage, while the Fe-6.5wt. The air-cooled cast strip has a slight plastic deformation, and the Fe-6.5wt.\%Si alloy watercooled cast strip has relatively obvious plastic deformation. The elongation is about $0.2 \%$, according to the room temperature tensile mechanical properties of Fe-6.5wt.\%Si alloy. The room temperature plasticity of Fe-6.5wt.\%Si alloy can be improved by reducing the order degree inside the body by rapid cooling, but the improvement of room temperature plasticity is not apparent.

Figure 8 shows the fracture morphologies of three room temperature tensile specimens. Figure $8 \mathrm{a}$ shows the room temperature tensile fracture morphology of the Fe- $6.5 \mathrm{wt}$.\%Si alloy ingot sample. As can be observed from the figure, there are a significant amount of cleavage steps and river patterns in the fracture, and the fracture mode of the ingot sample is mainly transgranular cleavage fracture. It can be seen from Fig. $8 \mathrm{~b}$ that there are still many river patterns in the room temperature tensile fracture of the aircooled cast strip sample, the cleavage step morphology disappears, and a small amount of ductile fracture zone appears. However, the room temperature plasticity of the air-cooled cast strip improved but was still dominated by cleavage fractures. From Fig. 8c, it can be seen that a few dimples appeared in the tensile fracture at room temperature of the water-cooled cast strip. However, a large number of river patterns could also be observed, which indicated that the room temperature plasticity of the water-cooled cast strip was further improved. However, The fracture mode is still dominated by cleavage fracture. The room temperature plasticity increases with the increase of cooling rate.

\section{Discussions}

Through the analysis of ordered phase morphology and degree of order, it is found that Fe-6.5wt.\%Si alloy ingot has the highest degree of order, Fe-6.5wt.\%Si alloy air-cooled cast strip has a lower degree of order, and Fe-6.5wt.\%Si alloy air-cooled cast strip has the lowest order. According to the phase diagram of Fe-Si alloy, Fe-6.5wt.\%Si alloy has $\mathrm{A}_{2}$ disordered structure above $760^{\circ} \mathrm{C}$, and with the decrease of temperature, $B_{2}$ ordered structure is formed in $A_{2}$ disordered matrix. Since the transition from $A_{2} \rightarrow B_{2}$ is secondary, the transition speed is faster. A further drop in temperature will lead to further ordering between the next-nearest neighbor atoms, and the $\mathrm{DO}_{3}$ ordered phase will nucleate in the existing $\mathrm{B}_{2}$ ordered phase domain. The transition from $\mathrm{B}_{2}$ to $\mathrm{DO}_{3}$ is a first-order transition, the time required for the transition longer than the transition time of $A_{2} \rightarrow B_{2}$ [23]. At the same time, due to the relatively simple lattice structure of the $B_{2}$ ordered phase, only one Fe atom and one Si atom can be formed [24]. During cooling, each pair of $\mathrm{Fe}$ atoms and one $\mathrm{Si}$ atom is the core of a $\mathrm{B}_{2}$ ordered phase, and this core grows rapidly so that it swallows up the surrounding similarly occupied lattice. Therefore, it is complicated to 
completely suppress the $\mathrm{B}_{2}$ ordered phase utilizing rapid cooling. The $\mathrm{DO}_{3}$ ordered phase has a higherorder and is a higher-order ordered phase formed based on the $\mathrm{B}_{2}$ ordered phase. The formation of a $\mathrm{DO}_{3}$ ordered phase unit cell requires more $\mathrm{Si}$ atoms to participate, and the temperature of this ordered region is lower $\left(<620^{\circ} \mathrm{C}\right)$, and the atomic mobility is poor. When the cooling rate is fast, the $B_{2}$ ordered phase cannot provide a sufficient basis for the nucleation and growth of the $\mathrm{DO}_{3}$ ordered phase. In addition, $\mathrm{Si}$ atoms are too late to occupy probabilistically in the way of the $\mathrm{DO}_{3}$ lattice, so $\mathrm{DO}_{3}$ has an ordered phase that can be quickly and completely suppressed. Due to the slow cooling rate of Fe-6.5wt.\%Si alloy ingots, smooth and curved $\mathrm{B}_{2}$ ordered phases and granular $\mathrm{DO}_{3}$ ordered phases were formed in the samples. Due to the fast cooling rate of the Fe-6.5wt.\%Si alloy air-cooled cast strip and water-cooled cast strip, the nucleation and growth of $\mathrm{DO}_{3}$ ordered phases in the samples can be easily and completely suppressed by rapid cooling. Although the $B_{2}$ ordered phase could not be completely inhibited, the growth of the $B_{2}$ ordered phase was inhibited.

Because the existence of the ordered phase will produce an ordered strengthening effect in the matrix, increasing the hardness and decreasing the plasticity of the material [25]. This is because, in ordered alloys, the movement of dislocations disrupts the ordered arrangement of atoms, creating additional antiphase domain boundaries on the slip plane. Yoshimi [26] investigated the effect of APB on the tensile properties of $\mathrm{Fe}_{3} \mathrm{Al}$ alloys and found that dislocations tend to aggregate at antiphase boundaries. They suggested that antiphase boundaries have some hindering effect on the movement of dislocations in the alloy. Since Fe-Si alloys have high antiphase boundary energy, dislocations tend to move in pairs to reduce the antiphase boundary energy of the system. Compared with ordinary unit dislocations in disordered alloys, superdislocations have larger slip resistance and insufficient independent slip systems during the movement process, resulting in reduced plasticity and poor processing performance $[27,28]$. The antiphase boundary energies decrease with decreasing ordering degrees, and the antiphase boundary energies affect the dislocation configuration in ordered alloys. The lower the antiphase boundary energy, the larger the distance of superdislocations, and the more favorable it is to decompose into single dislocations. Compared with paired superdislocations, single dislocations are easier to move and cross-slip. Thereby increasing the mobility of dislocations [29]. In Fe-6.5wt.\%Si alloy, the resistance of dislocation motion in the $\mathrm{DO}_{3}$ ordered phase is much larger than that in the $\mathrm{B}_{2}$ phase. That is to say, the mobility of dislocations in the $\mathrm{B}_{2}$ phase is high, while the mobility of dislocations in the $\mathrm{DO}_{3}$ phase is poor. In the $\mathrm{DO}_{3}$ phase, dislocations move slowly, and it is not easy to cross or bypass obstacles, resulting in superdislocations easily aggregated in grains or grain boundaries. Dislocations with different Burger vectors react to form a dislocation network, which further reduces the mobility of dislocations and becomes a new obstacle for other moving dislocations, thus forming a vicious circle. Therefore, in the present experiments, the variation in ductility and hardness of the Fe-6.5wt.\% Si alloy at room temperature can be attributed to the influence of ordered phases. The greater the content and size of the ordered phase, the worse the plasticity of the material. It can be seen from Fig. 9 that the ordered phase size is positively correlated with the hardness. In the Fe-6.5wt.\%Si alloy ingot sample, the $\mathrm{B}_{2}$ ordered phase has the largest size, and a larger $\mathrm{DO}_{3}$ ordered phase is observed. The Fe-6.5wt.\%Si alloy ingot has 
the largest hardness and the worst room temperature ductility. On the contrary, the hardness of the Fe$6.5 \mathrm{wt} . \% \mathrm{Si}$ alloy water-cooled cast strip is the smallest, and the room temperature plasticity is relatively the best.

In Fe-6.5wt.\%Si alloys, due to ordered phases in the matrix, the Burger vector of the total dislocations will become longer, resulting in the total dislocations becoming extremely unstable. Typically, a single global dislocation resolves into two, and four quantile dislocations in the $\mathrm{B}_{2}$ and $\mathrm{DO}_{3}$ ordered phases, respectively [30]. Figure 10 is a schematic diagram of the dislocation structure on the (110) close-packed plane in the ordered structure. In the $\mathrm{B}_{2}$ ordered structure, one complete dislocation decomposes into two dislocations, $b_{1}$ and $b_{2}$, connected by band-like APBs. Similarly, the $\mathrm{DO}_{3}$ ordered structure decomposes into four dislocations, $b_{1}, b_{2}, b_{3}$, and $b_{4}$, which are connected by two kinds of band-like APBs, namely $A P B_{1}$ and $A P B_{2}$. Ribbon $A P B s$ are energetic and proportional to the order of the matrix [29]. This means that the energy of banded APBs between paired superdislocations in Fe-6.5wt.\%Si alloy ingots is much higher than that of Fe-6.5wt.\%Si alloy air-cooled cast strip and water-cooled cast strip. The "ordered strengthening" effect occurs when the Fe-6.5wt.\%Si alloy undergoes plastic deformation. The $b_{1}$ dislocation in the $B_{2}$ structure will slip along the direction of the arrow in Fig. 10, and the ribbon APB will also be elongated, increasing the area of the APB, so additional energy is required to facilitate this process. Moreover, the higher the matrix order is, the higher the additional energy required. Similar processes will also occur in the $\mathrm{DO}_{3}$ ordered structure, but the $\mathrm{DO}_{3}$ ordered structure has a higher-order degree and requires more energy $[23,28]$. To sum up, this is also why the plasticity of Fe-6.5wt.\%Si alloy air-cooled cast strip and water-cooled cast strip is much higher than that of Fe-6.5wt.\%Si alloy ingot.

According to the above discussion, it can be known that the Fe-6.5wt.\%Si alloy ingot needs larger external stress to start slipping. However, before the superdislocations slip, the gradually increasing external stress will generate stress concentrations inside the material. When the strength of these stress concentrations exceeds the maximum strength of the matrix, macroscopic cracks will follow, Fe-6.5wt in Fig. 7. The stress-strain curve of the alloy ingot, which fractured in the form of cleavage fracture in the elastic stage, also confirmed the above inference. On the other hand, under the influence of a high degree of order, the intragranular stress concentration due to the difficulty of superdislocation slippage also makes Fe-6.5wt. The area of transgranular fracture [25] is consistent with the results of the fracture SEM fracture morphology in Fig. 8a.

\section{Conclusion}

By comparing Fe-6.5wt.\%Si alloys prepared by different processes, the microstructure and mechanical properties of $\mathrm{Fe}-6.5 \mathrm{wt} . \% \mathrm{Si}$ alloys were studied and analyzed. The effects of different preparation processes on the mechanical properties of ordered relative materials in Fe-6.5wt.\%Si alloys were also studied. Concluded as follow:

1. Fe-6.5wt.\%Si alloy as-cast strip prepared by TSTRC has good surface quality. The solidification structure of Fe-6.5wt.\%Si alloy water-cooled cast strip and air-cooled cast strip is much smaller than that 
of Fe-6.5wt.\%Si alloy as-cast ingot. Fe-6.5wt.\%Si alloy prepared by the TSTRC process has the advantage of refining solidification structure.

2. The deformation modes of the Fe-6.5wt.\%Si alloy cast strip samples in contact with the indenter are all Pile-up, and the hardness and work hardening index of the cast strip is low. The deformation mode of the Fe-6.5wt.\%Si alloy ingot in contact with the indenter is Sink-in. The hardness and work hardening index of the ingot are very high, reflecting the Fe-6.5wt.\%Si from the side. The ingot has the highest degree of order, the air-cooled cast strip has a low degree of order, and the water-cooled cast strip has the lowest degree of order.

3. The cooling rate of the Fe-6.5wt.\%Si alloy ingot is slow, so a smooth curved $\mathrm{B}_{2}$ ordered phase and a granular $\mathrm{DO}_{3}$ ordered phase are formed in the sample, with a high degree of order. The cooling rate of the Fe-6.5wt.\%Si alloy air-cooled cast strip and water-cooled cast strip is very fast. The nucleation and growth of the $\mathrm{DO}_{3}$ ordered phase in the sample can be easily completely suppressed by rapid cooling, and the growth of the $B_{2}$ ordered phase is also inhibited, the degree of order is relatively low.

4. The fracture mode of Fe-6.5wt.\%Si alloy prepared by three cooling methods at room temperature is mainly transgranular cleavage fracture. The Fe-6.5wt.\%Si alloy ingot has almost no plasticity at room temperature, and the Fe-6.5wt.\%Si alloy air-cooled cast strip and water-cooled cast strip have certain plasticity.

5. The solidification structure of the Fe-6.5wt.\%Si alloy cast strip is relatively fine, the content of the ordered phase is small, and the degree of order is low, which reduces the reverse domain boundary energy, reduces the motion resistance of super dislocations, and increases its possibility. Therefore, the room temperature plasticity of the Fe-6.5wt.\%Si alloy cast strip is improved.

\section{Declarations}

Authors' contributions Cheng Zhou contributed to the conception of the study; Dongpo Xuan performed the experiment, contributed significantly to analysis and manuscript preparation, performed the data analyses, and wrote the manuscript; Others helped perform the analysis with constructive discussions.

Funding This research did not receive any specific grant from funding agencies in the public, commercial, or not-for-profit sectors.

Data availability The data used to support the findings of this study are included within the article.

\section{Declarations}

Ethics approval and consent to participate Compliance with ethical standards. All authors agreed with the consent to participate.

\section{Consent to publish}


That the work described has not been published before (except in the form of an abstract or as part of a published lecture, review, or thesis).

That it is not under consideration for publication elsewhere;

That its publication has been approved by all co-authors, if any;

That its publication has been approved (tacitly or explicitly) by the responsible authorities at the institution where the work is carried out.

Competing interests The authors declare no competing interest.

\section{References}

1. Zhang, ZH, Wang WP, Fu HD, Xie JX (2011) Effect of quench cooling rate on residual stress, microstructure and mechanical property of an Fe-6.5Si alloy. Mat Sci Eng A 530:519-524. https://doi.org/10.1016/j.msea.2011.10.013

2. Littmann MF (1971) Iron and silicon-iron alloys. IEEE T Magn 7(1):48-60. https://doi.org/10.1109/TMAG.1971.1066998

3. Arai KI, Ishiyama K (1994) Recent developments of new soft magnetic materials. J Magn Magn Mater 133(1-3):233-237. https://doi.org/10.1016/0304-8853(94)90534-7

4. Li HZ, Liu HT, Liu Y, Liu ZY, Cao GM, Luo ZH, Zhang FQ, Chen SL, Li L, Wang GD (2014) Effects of warm temper rolling on microstructure, texture and magnetic properties of strip-casting $6.5 \mathrm{wt} \% \mathrm{Si}$ electrical steel. J Magn Magn Mater 370:6-12. https://doi.org/10.1016/j.jmmm.2014.06.053

5. Shin JS, Bae JS, Kim HJ (2005) Ordering-disordering phenomena and micro-hardness characteristics of B2 phase in Fe (5-6.5\%)Si alloys. Mat Sci Eng A 407(1/2):282-290. https://doi.org/10.1016/j.msea.2005.07.012

6. Liang YF, Ye F, Lin JP, Wang YL, Chen GL (2010) Effect of annealing temperature on magnetic properties of cold rolled high silicon steel thin sheet. J Alloy Compd 491(1-2):268-270. https://doi.org/10.1016/j.jallcom.2009.10.118

7. Li R, Shen Q, Zhang LM, Zhang T (2004) Magnetic properties of high silicon iron sheet Ffabricated by direct powder rolling. J Magn Magn Mater 281(2-3):135-139. https://doi.org/10.1016/j.jmmm.2004.04.098

8. Yuan WJ, Li JG, Shen Q, Zhang LM (2008) A study on magnetic properties of high Si steel obtained through powder rolling processing. J Magn Magn Mater 320(1-2):76-80. https://doi.org/10.1016/j.jmmm.2007.05.008 
9. Okada K, Yamaji T, Kasai K (1996) Basic investigation of cvd method for manufacturing $6.5 \% \mathrm{Si}$ steel sheet. ISIJ Int 36(6):706-713. https://doi.org/10.2355/isijinternational.36.706

10. Yamaji T, Abe M, Takada Y, Okada K, Hiratani T (1994) Magnetic properties and workability of $6.5 \%$ silicon steel sheet manufactured in continuous cvd siliconizing line. J Magn Magn Mater 133(13):187-189. https://doi.org/10.1016/0304-8853(94)90521-5

11. Abe M, Takada Y, Murakami T, Tanaka Y, Mihara Y (1989) Magnetic properties of commercially produced Fe-6.5wt\% Si sheet. J Mater Civil Eng 11(1):109-116. https://doi.org/10.1007/BF02833761

12. Arai KI, Tsutsumitake H, Ohmori K (1984) Grain growth and texture formation by annealing of rapidly quenched high silicon-iron alloy. J Jpn I Met Mater 48(5):482-488. https://doi.org/10.2320/jinstmet1952.48.5_482

13. Arai Kl, Tsuya N, Ohmori K, Shimanaka H, Miyazaki T (1980) Rapidly quenched ribbon-form siliconiron alloy with high silicon concentration. J Magn Magn Mater 15:1425-1426. https://doi.org/10.1016/0304-8853(80)90352-2

14. Fu HD, Zhang ZH, Yang Q , Xie JX (2011) Strain-softening behavior of an Fe-6.5 wt\%Si alloy during warm deformation and its applications. Mat Sci Eng A 528:1391-1395. https://doi.org/10.1016/j.msea.2010.10.093

15. Fu HD, Zhang ZH, Jiang YB, Xie JX (2011) Improvement of magnetic properties of an Fe-6.5wt.\% Si alloy by directional solidification. Mater Lett 65(9):1416-1419. https://doi.org/10.1016/j.matlet.2011.02.020

16. Xie JX, Fu HD, Zhang ZH, Jiang YB (2012) Deformation twinning feature and its effects on significant enhancement of tensile ductility in columnar-grained Fe-6.5wt.\%Si alloy at intermediate temperatures. Intermetallics 23:20-26. https://doi.org/10.1016/j.intermet.2011.12.011

17. Wang XL, Li HZ, Zhang WN, Liu ZY, Wang GD, Luo ZH, Zhang FQ (2016) The work softening by deformation-induced disordering and cold rolling of $6.5 \mathrm{wt} . \% \mathrm{Si}$ steel thin sheets. Metall Mater Trans A 47(9):4659-4668. https://doi.org/10.1007/s11661-016-3613-5

18. Raviprasad K, Chattopadhyay K (1988) The effect of rapid solidification on the order-disorder transformation in iron-based alloys. Mat Sci Eng A 98(98):281-284. https://doi.org/10.1016/00255416(88)90170-X

19. Gupta M, Sahai Y (2007) Mathematical modeling of fluid flow, heat transfer, and solidification in tworoll melt drag thin strip casting of steel. ISIJ Int 40(2):144-152. https://doi.org/10.2355/isijinternational.40.144

20. Liu HT, Liu ZY, Sun Y, Fei G, Wang GD (2013) Development of $\lambda$-Fiber recrystallization texture and magnetic property in $\mathrm{Fe}-6.5 \mathrm{wt} \% \mathrm{Si}$ thin sheet produced by strip casting and warm rolling method. Mater Lett 91(15):150-153. https://doi.org/10.1016/j.matlet.2012.09.046 
21. Wang D, Zhou C (2014) A top side-pouring twin-roll caster for metals strips. J Mater Process Tech 214(4):916-924. https://doi.org/10.1016/j.jmatprotec.2013.12.001

22. Alcalá J, Barone CA, Anglada M (2000) The influence of plastic hardening on surface deformation modes around vickers and spherical indents. Acta Mater 48:3451-3464. https://doi.org/10.1016/S1359-6454(00)00140-3

23. Marcinkowski MJ, Brown N (1962) Direct observation of antiphase boundaries in the Fe3Al superlattice. J Appl Phys 33(2):537-552. https://doi.org/10.1063/1.1702463

24. Ustinovshchikov Y I, Sapegina IV (2005) Ordering of Fe-Si phases. Inorg Mater 41(1):24-31. https://doi.org/10.1007/s10789-005-0006-3

25. Viala B, Degauque J, Fagot M, Baricco M, Ferrara E, Fiorillo F (1996) Study of the brittle behaviour of annealed Fe-6.5 wt\%Si ribbons produced by planar flow casting. Mat Sci Eng A 212(1):6268.https://doi.org/10.1016/0921-5093(96)10188-X

26. Yoshimi K, Terashima H, Hanada S (1995) Effect of APB type on tensile properties of $\mathrm{Cr}$ added Fe3Al with D03 structure. Mat Sci Eng A 194(1):53-61. https://doi.org/10.1016/09215093(94)09659-7

27. Marcinkowski MJ, Fisher RM (1963) Theoretical analysis of plastic deformation in superlattices based on the body-centered cubic structure. J Appl Phys 34(8):2135-2145. https://doi.org/10.1063/1.1702703

28. Marcinkowski MJ, Brown N (1961) Theory and direct observation of dislocations in the Fe3Al superlattices. Acta Metall 9(8):764-786. https://doi.org/10.1016/0001-6160(61)90107-9

29. Raviprasad K, Aoki K, Chattopadhyay K (1993) The nature of dislocations and effect of order in rapidly solidified Fe (5.5-7.5)wt.\%Si alloys. Mat Sci Eng A 172(1-2):125-135.

https://doi.org/10.1016/0921-5093(93)90432-E

30. Lakso, GE, Marcinkowski MJ (1974) Plastic deformation in Fe-Si alloys. Metall Mater Trans A 5(4):839-845. https://doi.org/10.1007/BF02643136

\section{Figures}

\section{Figure 1}

Schematic diagram of different preparation processes of Fe-6.5wt.\%Si alloy: $\mathbf{a}$ as-cast ingot, $\mathbf{b}$ air-cooled cast strip, and c water-cooled cast strip 
Figure 2

Solidification microstructure of Fe-6.5wt.\%Si alloy: $\mathbf{a}$ as-cast ingot, $\mathbf{b}$ air-cooled cast strip, and $\mathbf{c}$ watercooled cast strip
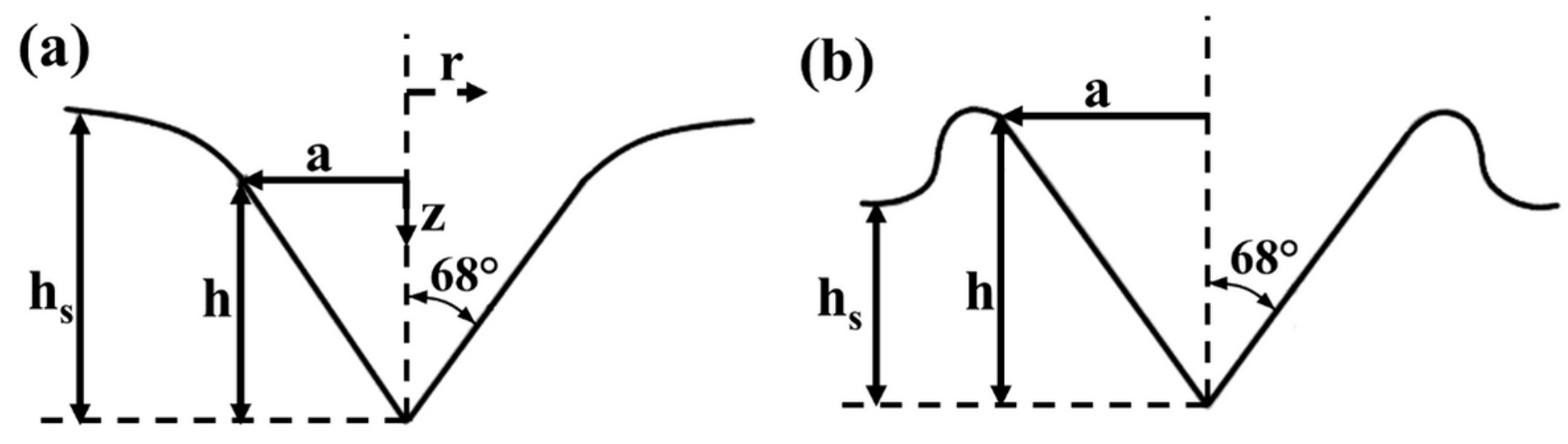

Figure 3

Schematic of pile-up and sink-in of material around the Vickers indenter: $\mathbf{a}$ sink-in, $\mathbf{b}$ pile-up
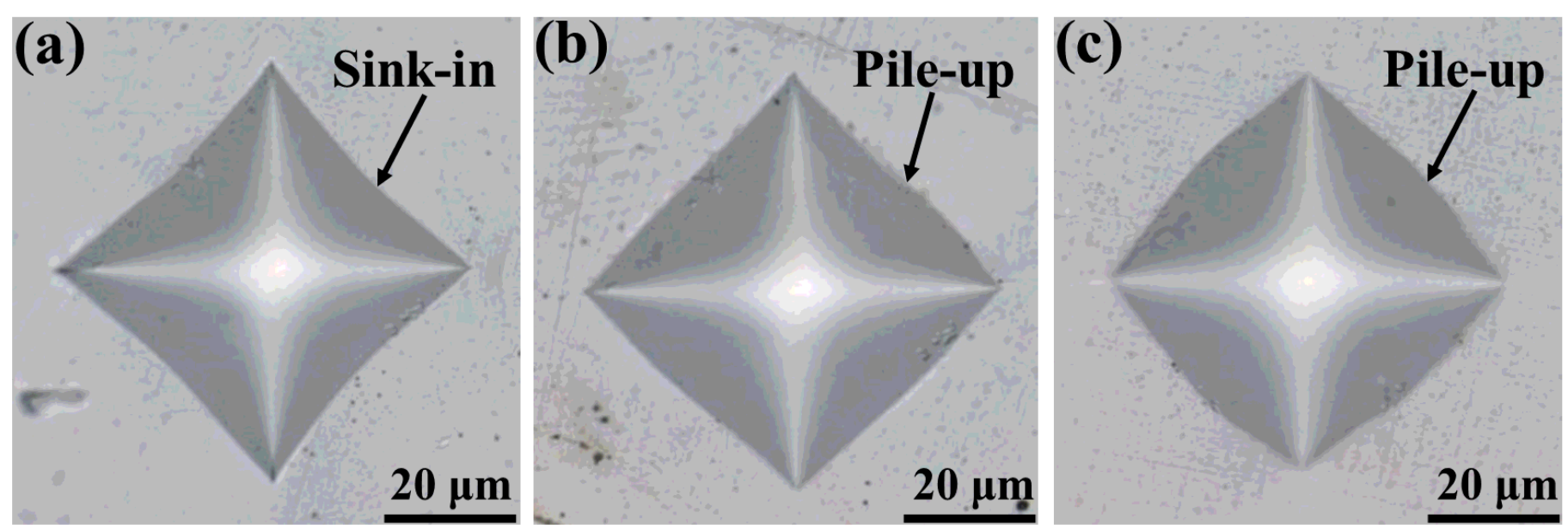

Figure 4

Microhardness indentation surface morphology of Fe-6.5wt.\%Si alloy: a as-cast ingot, $\mathbf{b}$ air-cooled cast strip, and c water-cooled cast strip 


\section{Figure 5}

XRD spectra of Fe-6.5wt.\%Si alloy prepared by different cooling methods

\section{Figure 6}

The SAED pattern and dark field image of Fe-6.5wt.\%Si alloy [110] crystal belt axis: a as-cast ingot, $\mathbf{b}$ aircooled cast strip, and $\mathbf{c}$ water-cooled cast strip

\section{Figure 7}

Room temperature tensile curves of Fe-6.5wt.\%Si alloy: $\mathbf{a}$ as-cast ingot, $\mathbf{b}$ air-cooled cast strip, and $\mathbf{c}$ water-cooled cast strip

\section{Figure 8}

Room temperature tensile fracture morphology of Fe-6.5wt.\%Si alloy: $\mathbf{a}$ as-cast ingot, $\mathbf{b}$ air-cooled cast strip, and c water-cooled cast strip

\section{Figure 9}

Hardness and ordered phase size of Fe-6.5wt.\%Si alloy under different cooling methods

\section{Figure 10}


The structure of super-dislocation on the (110) slip plane in ordered structures: $\mathbf{a} \mathrm{B}_{2}$ ordered phase, $\mathbf{b} \mathrm{DO} \mathrm{O}_{3}$ ordered phase 